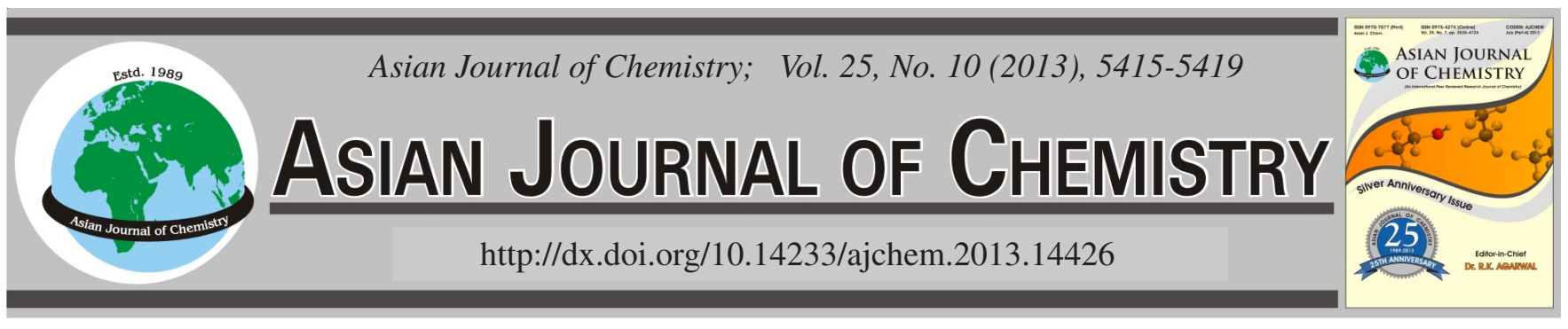

\title{
Synthesis and Characterization of Photoelectrocatalytic Electrodes for Methylene Blue Degradation
}

\author{
Won-Chun OH ${ }^{1, *}$, Jong-Gyu Kim ${ }^{2}$, Hyuk Kim ${ }^{2}$, Chong-Yeon Park ${ }^{1}$, Lei Zhu ${ }^{1}$, \\ Kefayat Ullah ${ }^{1}$, Shu Ye ${ }^{1}$ and Ze-Da Meng ${ }^{1}$
}

${ }^{1}$ Department of Advanced Materials \& Science Engineering, Hanseo University, Seosan-si, Chungnam-do 356-706, South Korea
${ }^{2}$ Hanil Green Tech Co, Ltd, Buyeo-gun, Chungnam-do 323-82, South Korea

*Corresponding author: Fax: +82 41 6883352; Tel: +82 41 6601337; E-mail: wc_oh@hanseo.ac.kr

\begin{abstract}
In this study, series of electrodes were prepared. The decrease of surface area compared with that of the pristine activated carbon indicated the blocking of micropores on the surface of the activated carbons; was further supported by scanning electron microscopy. The X-ray diffraction results showed that the composites contained a mixture of anatase forms of $\mathrm{TiO}_{2}$ particles when the precursor was $\mathrm{TiO}_{2}$ powder, whereas when the precursor was TOS, the composites contained only the typical single and clear anatase $\mathrm{TiO}_{2}$ particles. The energy dispersive X-ray spectroscopy showed the presence of $\mathrm{C}, \mathrm{O}$ and Ti peaks for all samples. It was found that catalytic decomposition of methylene blue solution could be attributed to synthetic effects between the $\mathrm{TiO}_{2}$ photocatalysis and electro-assisted ACs network and that photoelectrocatalytic oxidation increased with added of Co and graphene composition.
\end{abstract}

Key Words: $\mathrm{AC} / \mathrm{TiO}_{2}$ electrode, Photoelectrocatalysis, Methylene blue, Visible light, Ultrasonic.

\section{INTRODUCTION}

The use of heterogeneous photocatalysis for the nonselective destruction of organic and inorganic waste materials has been widely demonstrated in numerous laboratory studies. Organic compounds such as chlorinated alkanes and alkenes, polychlorinated phenols, aromatics, aldehydes, organic acids and amines can be oxidized to carbon dioxide, water and mineral acids using near-UV or light illuminated $\mathrm{TiO}_{2}$ particles ${ }^{1}$. However, the low photocatalytic efficiency has limited the application of this technology in practical treatment ${ }^{2-5}$.

Activated carbon (AC) was made excellent alternative because it could concentrate pollutants through adsorption around the loaded $\mathrm{TiO}_{2}$ leading to an increase in the degradation of the pollutants ${ }^{6}$. Moreover AC is low cost can reduce the cost of photocatalyst. In addition, the interaction between pollutants and the surface of $\mathrm{AC} / \mathrm{TiO}_{2}$ was also enhanced to further promote the degradation ${ }^{7}$. Consequently, $\mathrm{AC} / \mathrm{TiO}_{2}$ is considered to be a promising photocatalyst with an industrial application prospect ${ }^{8}$.

The photocatalytic (PC) method was based on the reactive properties of photogenerated electron-hole pairs. They were generated in the semiconductor $\left(\mathrm{TiO}_{2}\right)$ particles under UV irradiation, at the same time these electrons and holes could also recombine. Since the hole was a powerful oxidizing agent, it could decompose water and/or contaminants adsorbed on the $\mathrm{TiO}_{2}$ surface.

However, the $\mathrm{AC} / \mathrm{TiO}_{2}$ photocatalyst above present seems to have the application form of particles, which time consuming for the particle-fluid separation after radiation treatment for the reuse of the catalyst restrained its industrial applications. So development of $\mathrm{TiO}_{2}$ photocatalysts immobilized on a certain suitable electrode such as CNT electrode would be of great significance, not only to avoid the disadvantages of filtration of fine photo catalyst particles, but to lead to high photodecomposition efficiency $^{9,10}$. There were many reports on photoelectrocatalytic (PEC) degradation of organic pollutants using $\mathrm{TiO}_{2}$ composite electrodes, which were prepared by coating the surfaces of electrically conducting substrates with $\mathrm{TiO}_{2}$ films ${ }^{11,12}$. In this method, a positive potential was applied on the working electrode, which could inhibit the recombination of electron/hole pairs and enhance the rate of PEC degradation activity for organic compounds ${ }^{13,14}$. ACs were selected as the support materials for catalyst deposition to prepare PEC electrodes that have large surface area, better catalyst dispersion and a high electro activity. Therefore, ACs have been proposed as a promising candidate as the support materials for $\mathrm{TiO}_{2}$ catalyst depositions.

Many studies have been devoted to fabrication of noble metals (such as $\mathrm{Pt}, \mathrm{Pd}, \mathrm{Co}$ and $\mathrm{Au}$ ) nanoparticle-decorated 
carbons as well as measuring their unique electrical, magnetic and optical properties ${ }^{15,16}$. These metal ions have reduction potentials that are more positive than the conduction band edges of common semiconductors. Metal cations whose potentials do not permit their reduction can be oxidized and deposited on the semiconductor as insoluble oxides photogenerated electrons and holes participate in redox reactions with adsorbed species on the semiconductor surface such as hydroxyl ions, water molecules, dissolved oxygen molecules, organic species and metal ions.

Two-dimensional (2-D) graphene has emerged as high potential material and increasingly attracted attention owing to its fascinating physical properties including quantum electronic transport, extremely high mobility, high elasticity and electromechanical modulation ${ }^{17}$.

In this study, we focused on the preparation and characterization of the $\mathrm{AC} / \mathrm{TiO}_{2}, \mathrm{AC} / \mathrm{G} / \mathrm{TiO}_{2}$ and $\mathrm{AC} / \mathrm{G} / \mathrm{Co} / \mathrm{TiO}_{2}$ composites electrodes. The electrodes were synthesized. The prepared electrodes were characterized by BET surface area, $\mathrm{X}$-ray diffraction (XRD), scanning electron microscope (SEM), energy dispersive X-ray (EDX). The catalytic efficiency of the prepared electrode was evaluated by the photoelectron degradation of an azo compound, methylene blue $\left(\mathrm{MB}, \mathrm{C}_{16} \mathrm{H}_{18} \mathrm{~N}_{3} \mathrm{SCl} \cdot 3 \mathrm{H}_{2} \mathrm{O}\right)$. Moreover, piggery waste was used to investigate the degradation effect of waste.

\section{EXPERIMENTAL}

All chemicals were used as received without further purification. Active carbon was purchased from coconut. The coconut shell was pre-carbonized first at $773 \mathrm{~K}$ and then activated by steam diluted with nitrogen in a cylindrical quartz tube at $1023 \mathrm{~K}$ for $0.5 \mathrm{~h}$. This $\mathrm{AC}$ was washed with deionized water and dried overnight in a vacuum drier at over $683 \mathrm{~K}$. $\mathrm{TiOSO}_{4} \cdot \mathrm{xHO}_{2}$ (TOS) were purchased from Solvachim and Merck, respectively. Cobalt chloride $\left(\mathrm{CoCl}_{2}\right)$ was purchased from DaeJung Chemicals \& Metal Co., Ltd., Korea. $\mathrm{H}_{2} \mathrm{O}_{2}$ was purchased from Daejung Chemicals Metals Co., Ltd. and were used to dissolve the TOS. Methylene blue was supplied by Duksan Pure Chemical Co., Ltd. The novolac typed phenol resin (PR) was supplied from Kangnam Chemical Co., Ltd., Korea.

Preparation of different composites: Active carbon was mulled for $5 \mathrm{~h}$ and treated with phosphoric acid (0.1 M $1 \mathrm{~L})$, drying at $373 \mathrm{~K}$ for $5 \mathrm{~h}$. Carbon granules were prepared. Due to TOS was easily dissolved by oxydol solution, 6,8 and $10 \mathrm{~g}$ TOS were added to $300 \mathrm{~mL}$ of oxydol, respectively. After stirring for $1 \mathrm{~h}$, TOS- $\mathrm{H}_{2} \mathrm{O}_{2}$ solution was obtained. And then AC granules were added to each TOS- $\mathrm{H}_{2} \mathrm{O}_{2}$ solution, respectively. Mix up the mixture for $1 \mathrm{~h}$. Then the supported $\mathrm{TiO}_{2}$ particles were first dried at $273 \mathrm{~K}$ for $6 \mathrm{~h}$ and calcined at 773 $\mathrm{K}$ for $2 \mathrm{~h}$ each. $\mathrm{AC} / \mathrm{TiO}_{2}$ photocatalyst composites were obtained. The designations for different prepared materials are summarized in Table-1.

$55 \mathrm{~g}$ carbon granules were mixed with $50 \mathrm{~mL}$ cobalt chloride solution $(0.1 \mathrm{M})$. After strring $1 \mathrm{~h}$ and dring at $373 \mathrm{~K}$, the mixture was heat treatment at $773 \mathrm{~K}$. And then Co-AC compounds were formed. TOS treated method as above.

\begin{tabular}{|c|c|c|}
\hline \multicolumn{3}{|c|}{$\begin{array}{l}\text { TABLE-1 } \\
\text { PREPARATION METHOD AND NOMENCLATURE } \\
\text { AND BET SURFACE AREA }\end{array}$} \\
\hline Preparation methods (\%) & Nomenclature & $\mathrm{S}_{\mathrm{BET}}\left(\mathrm{m}^{2} / \mathrm{g}\right)$ \\
\hline $\mathrm{AC}(58)+\mathrm{PR}(40)$ & AP3 & 647 \\
\hline $\begin{array}{lll}\mathrm{AC}(92)+ & \mathrm{AO} 3 & \mathrm{AO} 3(60)+ \\
\mathrm{TOS}(10) & & \mathrm{PR}(40 \%) \\
\end{array}$ & AOP3 & 629 \\
\hline $\mathrm{AO} 3(65)+\mathrm{Gr}(10)+\mathrm{PR}(25)$ & AGP2 & 542 \\
\hline $\begin{array}{l}\mathrm{AO} 3(55)+\mathrm{Co}(10)+\mathrm{Gr}(10)+\mathrm{PR} \\
(25)\end{array}$ & ACGP & 502 \\
\hline
\end{tabular}

Preparation of electrodes: The phenol resin was added into these different composites and the composites were pressed at a pressure of $250 \mathrm{~kg} / \mathrm{cm}^{2}$ in a mould (Fig. 1) into a dimension of $150 \mathrm{~mm} \times 300 \mathrm{~mm} \times 20 \mathrm{~mm}$. The electrodes were obtained agree heat treatment at $673 \mathrm{~K}$ for $1 \mathrm{~h}$. The preparation condition and nomenclatures of sample are listed in Table-1.

Characterization of compounds: For the measurement of structural variations, XRD patterns were taken using an $\mathrm{X}$-ray generator (Shimadzu XD-D1, Japan) with $\mathrm{CuK}_{\alpha}$ radiation. SEM was used to observe the surface state and structure of composites using a scanning electron microscope (JSM-5200 JOEL, Japan). Energy dispersive X-ray (EDX) spectroscopy was also used for the elemental analysis of the samples. The $\mathrm{N}_{2}$ adsorption isotherm was measured at $77 \mathrm{~K}$ using a BEL sorp Analyzer (BEL, Japan). The absorbance spectrums of the photocatalyst were recorded at room temperature in the range 300-800 nm using a UV-VIS spectrophotometer (Genspec III, Hitachi, Japan) equipped with an integration sphere. Finally, the COD analyses were measured with a cell test spectrophotometer (PhotoLab S6, WTW, Germany) in accordance with standard cell teat methods (Merck, Germany).

Photoelectrocatalytic degradation: The PEC degradation was performed using various electrodes in a container and then irradiating the system with UV light, visible light and ultrasonic (Fig. 2). The distance from the light to the solution was $50 \mathrm{~mm}$ in darkness room. The counter electrode was artificial graphite with a dimension of $150 \mathrm{~mm} \times 300 \mathrm{~mm} \times 20 \mathrm{~mm}$. The electrode was placed in $2 \mathrm{~L}$ of $1.0 \times 10^{-5} \mathrm{~mol} / \mathrm{L} \mathrm{MB}$ solution. The PEC degradation of methylene blue was performed with a voltage of $6.0 \mathrm{~V}$ and irradiating (Fig. 1). The blue colour of the solution faded gradually with time, owing to an adsorption and degradation of MB solution. The concentration of MB in the solution was determined as a function of irradiation time from the absorbance change at a wavelength of $660 \mathrm{~nm}$.

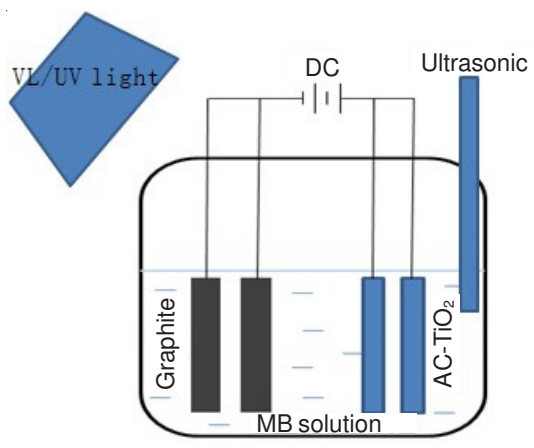

Fig. 1. Schematic diagram of reactor 


\section{RESULTS AND DISCUSSION}

Surface characteristics of the samples: The micro-surface structures and morphologies of the four different composites were exhibited via SEM image (Fig. 2). The SEM technique is used for inspecting topographies of specimens at very high magnifications using a piece of equipment called the scanning electron microscope. Fig. 4 shows the macroscopic changes in the morphology of the composites. In Fig. 4 particles have a small particle size and a good dispersion and the AC particles are shown as spherical particles with small facets and a good dispersion ${ }^{18}$. Zhang et al. ${ }^{19}$ reported that a good dispersion of small particles could provide more reactive sites for the reactants than aggregated particles.

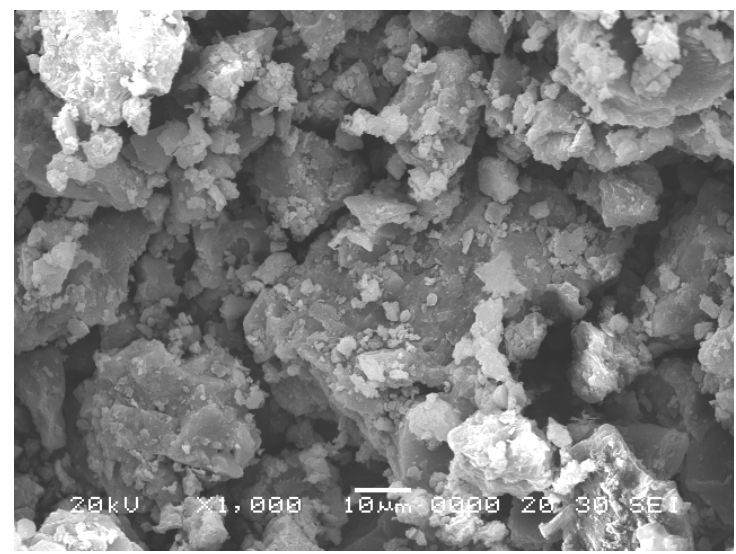

(a)

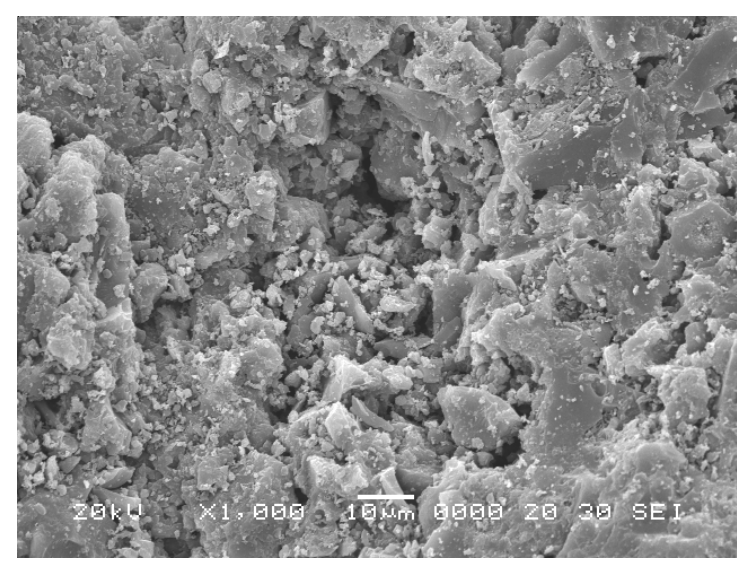

(b)

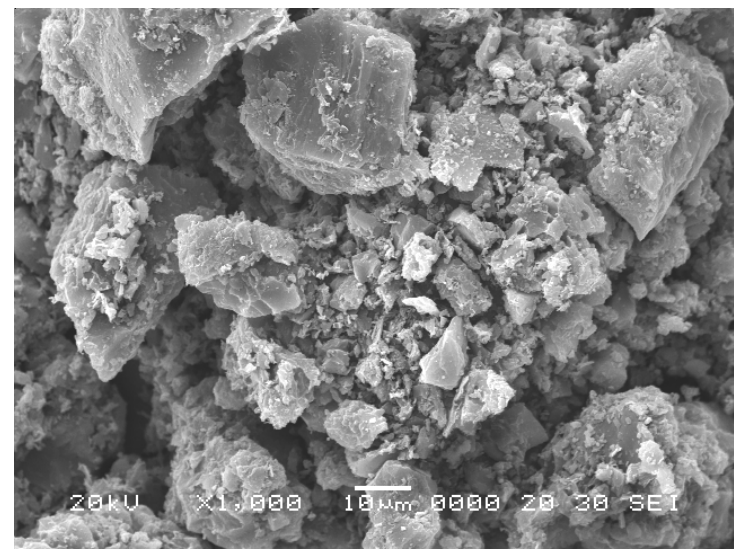

(c)

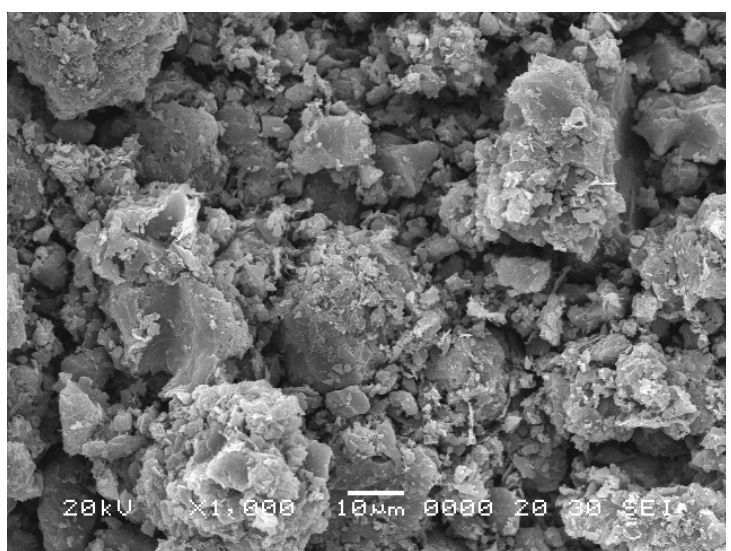

(d)

Fig. 2. SEM images of (a) AP3, (b) AOP3, (c) AGP2 and (d) ACGP

Table-1 lists the specific surface area (BET) of the materials examined. The BET surface area of AC was $856 \mathrm{~m}^{2} / \mathrm{g}$. when $\mathrm{TiO}_{2}$ particles were added, the BET value decreased to $642 \mathrm{~m}^{2} / \mathrm{g}$ but the surface area of AGP was $580 \mathrm{~m}^{2} / \mathrm{g}$. $\mathrm{TiO}_{2}$ particles were introduced into the pores of $\mathrm{AC}$, which decreased the BET surface area. AC and graphene contains many pores and can increase the surface area of the photocatalyst. The BET surface area decreased from $580 \mathrm{~m}^{2} / \mathrm{g}$ for AGP to 502 $\mathrm{m}^{2} / \mathrm{g}$ for ACGP. This suggests that the $\mathrm{TiO}_{2}$ and Co were introduced into the pores of the $\mathrm{AC}$ and graphene, which decreased the BET surface area.

Elemental analysis of the preparation: Fig. 3 shows the EDX patterns of the four different composites. EDX indicated $\mathrm{C}, \mathrm{O}$ and $\mathrm{Ti}$ as the major elements in the composites. Fig. 3(a) shows the presence of $\mathrm{C}$ and $\mathrm{O}$ as major elements. Fig. 3(b) and (c) shows the presence of $\mathrm{C}$ and $\mathrm{O}$ as major elements with strong Ti peaks. Fig. 3(d) shows the presence of $\mathrm{C}$ and $\mathrm{O}$ as major elements with strong Ti and Co peaks. There were some small impurities, which were attributed to the use of TOS, carbon or $\mathrm{CoCl}_{2}$ without purification.

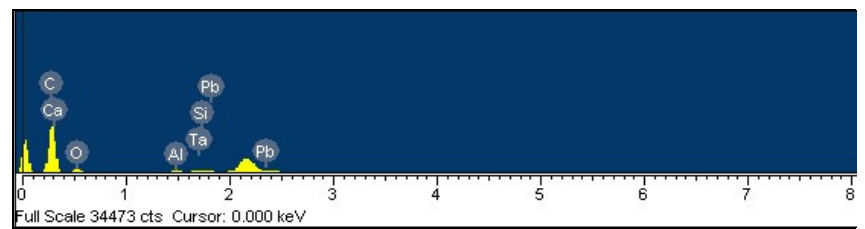

(a)

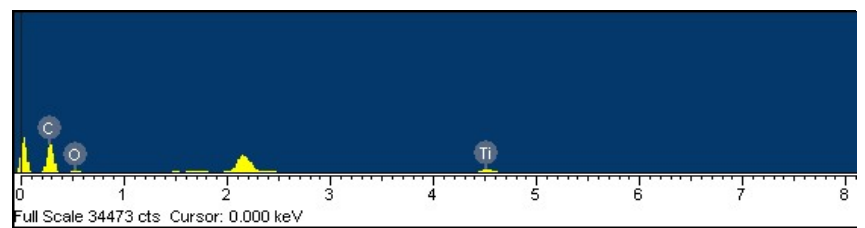

(b)

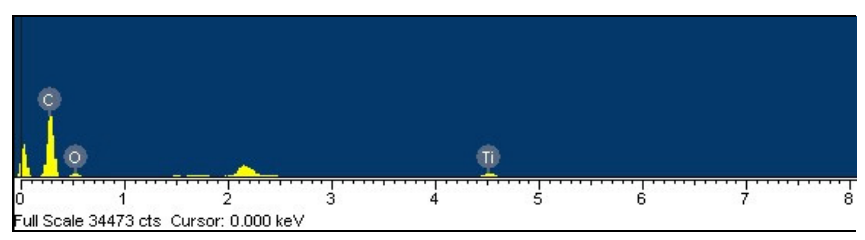

(c) 


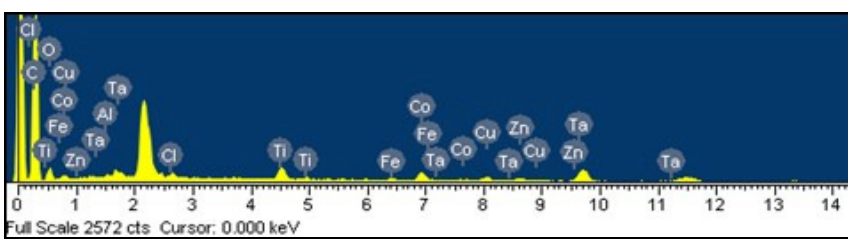

(d)

Fig. 3. EDX elemental microanalysis for (a) AP3, (b) AOP3, (c) AGP2 and (d) ACGP

Structural analysis: XRD was used to determine the crystallographic structure of the inorganic component of the composite. Fig. 4 shows the XRD patterns of the samples. In Fig. 4, $\mathrm{A}$ is anatase, $\mathrm{C}$ is carbon and $\mathrm{G}$ is graphite. The structure of AOP3, AGP2 and ACGP composites showed anatase $\mathrm{TiO}_{2}$. The crystal structure of $\mathrm{TiO}_{2}$ is determined mainly by the heat treated temperature. The peaks at 25.3, 37.5, 48.0, 53.8, 54.9 and $62.5^{\circ} 2 \theta$ were assigned to the (101), (004), (200), (105), (211) and (204) planes of anatase ${ }^{20}$. The peaks assigned of Co and $\mathrm{Co}_{3} \mathrm{O}_{4}$ can be found at ACGP composites.

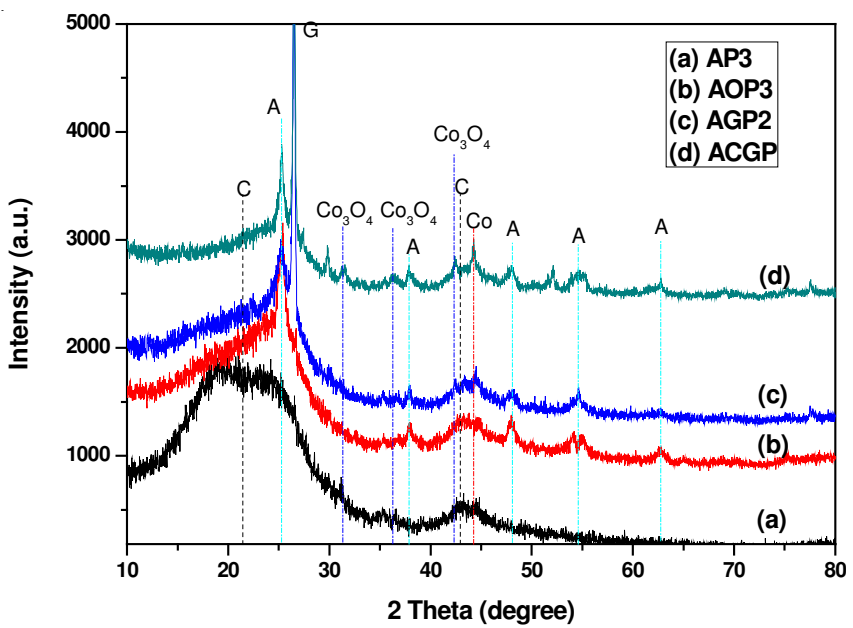

Fig. 4. XRD patterns of (a) AP3, (b) AOP3, (c) AGP2 and (d) ACGP, A is anatase, $\mathrm{C}$ is carbon and $\mathrm{G}$ is graphite

Photocatalytic activity of samples: Two steps are inolved in the photocatalytic decomposition of dyes, the adsorption of dye molecules and their degradation. After adsorption in the dark for $2 \mathrm{~h}$, all the samples reached adsorption-desorption equilibrium. The photodegradation followed first-order kinetics. The kinetics can be expressed as follows: - $\ln \left(\mathrm{C}_{\mathrm{t}} / \mathrm{C}_{0}\right)=\mathrm{k}_{\mathrm{app}} \mathrm{t}$, where $\mathrm{k}_{\text {app }}$ is the apparent reaction rate constant, $\mathrm{C}_{0}$ and $\mathrm{C}_{\mathrm{t}}$ are the initial concentration and the reaction concentration of $\mathrm{MB}$, respectively ${ }^{21,22}$. Fig. 5 shows the changes in relative concentration $\left(\mathrm{C}_{\mathrm{t}} / \mathrm{C}_{0}\right)$ of the different composites in MB concentration of $1 \times 10^{-5}$ under different conditions in the aqueous solution. Fig. 5(a) shows different electrodes degradation of MB solution under electrolysis and sonolysis condition. Fig. 5(b) shows different electrodes on the degradation of MB solution under electrolysis and photolysis condition (UV light). Fig. 5(c) shows different electrodes on the degradation of MB solution under electrolysis and photolysis condition (VL light). From the present results in Fig. 5, it can be seen that the PEC process of MB with fast degradation efficiency of ACGP was observed. Furthermore, we also used the piggery waste to determine the photocatalytic activity for the composites by

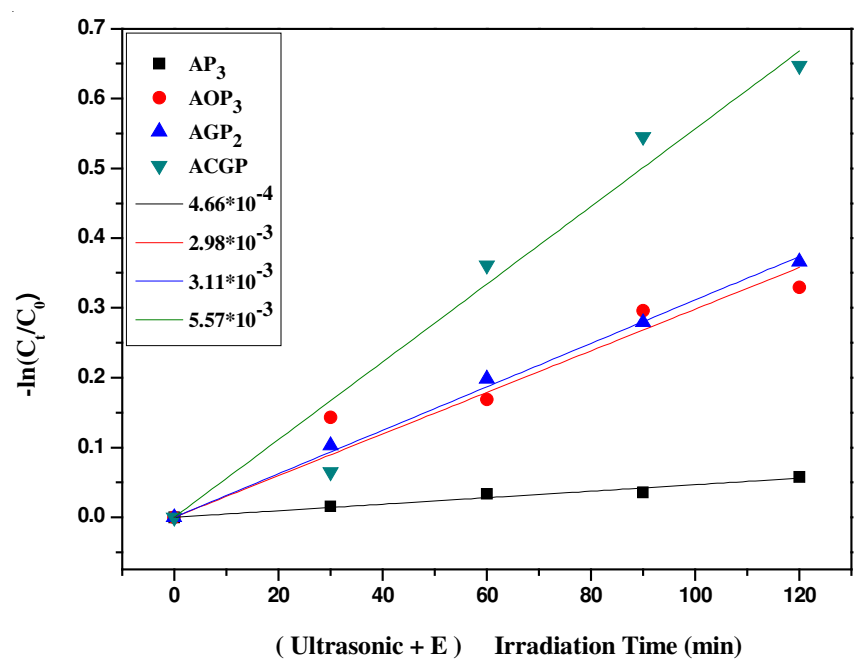

(a)

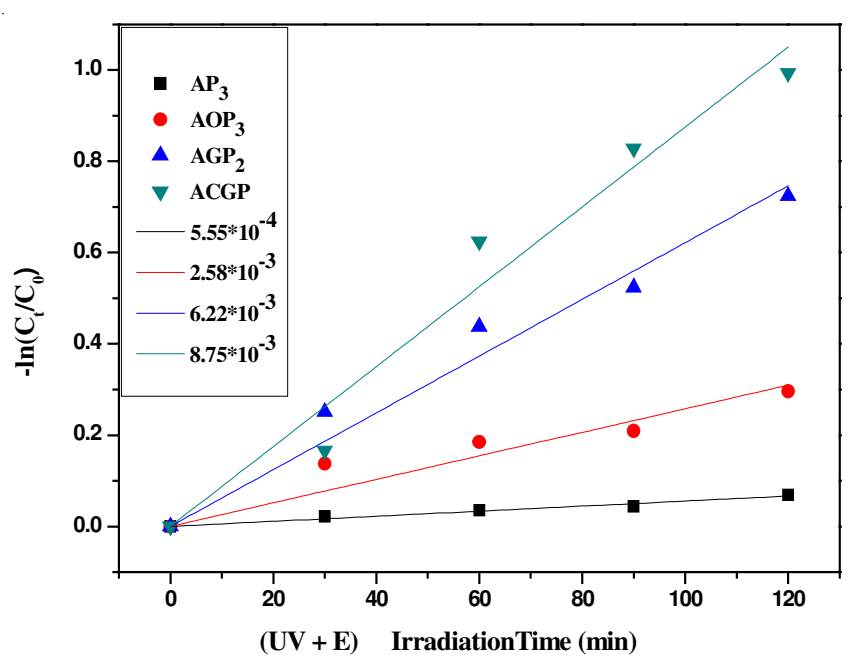

(b)

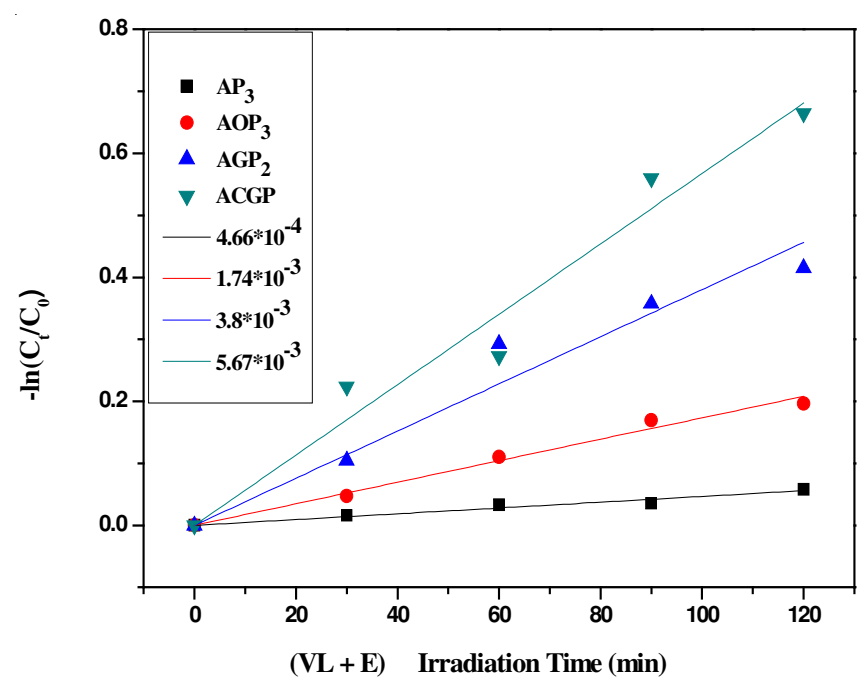

(c)

Fig. 5. (a) Variations in $-\ln \left(\mathrm{C}_{t} / \mathrm{C}_{0}\right)$ as a function of irradiation time and linear of different electrodes on the degradation of $\mathrm{MB}$ solution under electrolysis and sonolysis condition. (b) degradation of MB solution under electrolysis and photolysis condition (UV light). (c) degradation of MB solution under electrolysis and photolysis condition (VL light) 
using the COD and BOD. ACGP has a good degradation rate due to the higher efficiency.

The synergetic effect of AC on the activity of the AC/ $\mathrm{TiO}_{2}$ composite catalysts can be ascribed. As known, a large surface area may be an important factor in certain photocatalytic degradation reactions, as a large amount of adsorbed organic molecules promotes the reaction rate. AC acts as the adsorb effect and increases the surface area of the compounds which can increase the adsorption effect for samples, adsorbing more $\mathrm{O}_{2}$ and dye molecules and ensuring these systems take full advantage of yield oxidizing species. Doping $\mathrm{TiO}_{2}$ with carbon (AC) extends the absorption wavelengths from UV to visible region, which has been ascribed to the introduction of localized electronic states in the band gap. Carbon acted as a photosensitizer, which could be excited to inject electrons into the conduction band of $\mathrm{TiO}_{2}{ }^{23}$. Subsequently, the electrons could be transferred to surface-adsorbed oxygen molecules and form superoxide anions, which could further transform to $\mathrm{OH}^{\bullet}$ and initiate the degradation of MB. It is additional reason that removal effect of organic materials in solution was also governed by physisorption by porous AC. Electrons transfer between carbon materials and $\mathrm{TiO}_{2}$ semiconductor. Simultaneously, a positive charged hole $\left(\mathrm{h}^{+}\right)$might be formed by electron migrating from $\mathrm{TiO}_{2}$ valence band to $\mathrm{AC}$. With this understanding, the role played by $\mathrm{AC}$ can be illustrated by injecting electrons into $\mathrm{TiO}_{2}$ conduction band under light irradiation and triggering the formation of very reactive radicals superoxide radical ion $\mathrm{O}^{--}$and hydroxyl radical $\mathrm{HO}^{\circ}$, which are responsible for the degradation of the organic compound. The Co has excited electrical conductivity and can act as a transmitter and enhance the photogenerate electrical transfer effect, thus increasing the photocatalytic activity. The presence of Co is believed to retard $\mathrm{e}^{-} / \mathrm{h}^{+}$pairs recombination by serving as an electron sink (schottky-barrier electron trapping) and to facilitate the interfacial electron transfer to dioxygen or other electron acceptors. Because of sonoluminescence effect of ultrasonic irradiation, so in the ultrasonic irradiation process generated a lot of generated light. Be similar to the photocatalytic degradation, the sonocatalytic method also needs to restrain the recombination of electron-hole pair ${ }^{24,25}$.

Furthermore, it was considered that the recombination of photogenerated $\mathrm{e}^{-} / \mathrm{h}^{+}$pairs was suppressed by the externally applied electric field in the PEC reaction. Thus, the life of the $\mathrm{e}^{-} / \mathrm{h}^{+}$prolonged so that electrons are able to migrate to the solid-liquid interface and promote redox reactions. At the same time, the holes are removed via their reaction with $\mathrm{MB}$ in the solution, which occurs only at $\mathrm{TiO}_{2}$ solution interfaces. The photocatalytic reaction occurs when $\mathrm{HO}$ o radical reacts with MB molecule.

In this study, it was considered that the PEC degradation of MB solution could be attributed to synergetic effects of photo-degradation of $\mathrm{TiO}_{2}$, electro-assistance of $\mathrm{AC}$, enhancement of $\mathrm{Co}$, graphene and function of applied potential. It can be concluded that this expatiation for the degradation mechanism is in accord with results of MB degradation by PEC using the composite electrodes. ACGP has a good degradation rate due to the higher efficiency for the electron hole regeneration and the charge trapping and the inhibition of the electron-hole pair recombination in this system.

\section{Conclusion}

The fabrication and characterization of the composites electrodes were presented. The BET surface areas for the AC/ $\mathrm{TiO}_{2}$ composites decreased with added of $\mathrm{TiO}_{2}$ components. XRD data revealed that the structure for the composites showed a anatase crystals of $\mathrm{TiO}_{2}$. From the EDX data, the main elements such as $\mathrm{C}, \mathrm{O}, \mathrm{Ti}$ and $\mathrm{Co}$ were found. The samples have a higher PEC degradation efficiency than that of non-treated $\mathrm{AC} / \mathrm{TiO}_{2}$ sample (AP3). Moreover, among the four samples of composites, the PEC degradation efficiency of the sample ACGP was the best. COD and BOD result also revealed that degradation efficiency of the sample ACGP was the best. The results demonstrated that the PEC degradation of MB solution could be attributed to synergetic effects of photo-degradation of $\mathrm{TiO}_{2}$, electro-assistance of AC networks, enhancement of Co, graphene and function of applied potential.

\section{ACKNOWLEDGEMENTS}

This work was supported by the Academic-Industrial Cooperation Technique Development Support Project supervised from the Small and Medium Business Administration in 2011. The authors are grateful to the Small and Medium Business Administration for financial support.

\section{REFERENCES}

1. W.C. Oh, F.J. Zhang and M.L. Chen, J. Ind. Eng. Chem., 16, 299 (2010).

2. M.L. Chen, F.J. Zhang, K. Zhang, Z.D. Meng and W.C. Oh, Elas. Comp., 45, 25 (2010)

3. Y. Yang, X. Li, J. Chen and L. Wang, J. Photochem. Photobiol. A, 163, 517 (2004).

4. J.M. Herrmann and C. Guillard, Acad. Sci. Paris Ser. IIc., 3, 417 (2000).

5. M.R. Hoffmann, S.T. Martin, W. Choi and D.W. Bahnemann, Chem. Rev., 95, 69 (1995).

6. Z.D. Meng, K. Zhang and W.C. Oh, J. Korean Cryst. Grow. Cryst. Technol., 19, 268 (2009).

7. D. Duonghong, E. Borgarello and M. Gratzel, J. Am. Chem. Soc., 103, 4685 (1981).

8. W.C. Oh, J.H. Son, F.J. Zhang and M.L. Cheng, J. Korean. Ceram. Soc., 46, 1 (2009).

9. F.J. Zhang, M.L. Chen and W.C. Oh, Korean J. Mater. Res., 18, 583 (2008).

10. F.J. Zhang, M.L. Chen and W.C. Oh, New Carbon Mater., 25, 348 (2010).

11. P.A. Christensen, T.P. Curtis and T.A. Egerton, Appl. Catal. B, 41, 371 (2003).

12. X.Z. Li, F.B. Li and C.M. Fan, Water Res., 36, 2215 (2002).

13. X.Z. Li, H.L. Liu and P.T. Yue, Environ. Sci. Technol., 34, 4401 (2000).

14. F.Y. Oliva, L.B. Avalle and E. Santos, J. Photochem. Photobiol. A: Chem., 146, 175 (2002).

15. G.G. Wildgoose, G.E. Banks and R.G. Compton, Small, 2, 182 (2006).

16. V. Georgakilas, D. Gournis and V. Tzitzios, J. Mater. Chem., 17, 2679 2007.

17. M.F. Lin and F.L. Shyu, J. Phys. Soc. (Japan), 69, 3529 (2000).

18. Z.D. Meng, L. Zhu, J.G. Choi, C.Y. Park and W.C. Oh, Nanoscale Res. Lett., 6, 459 (2011).

19. X.W. Zhang, M.H. Zhou and L.C. Lei, Carbon, 43, 1700 (2005)

20. W.C. Oh, J. Photocatal. Sci., 1, 29 (2010).

21. Z.D. Meng, L. Zhu, J.G. Choi, F.J. Zhang and W.C. Oh, J. Mater. Chem., 21, 7596 (2011).

22. Z.D. Meng, M.M. Peng, L. Zhu, W.C. Oh and F.J. Zhang, Appl. Catal. B, 113-114, 141 (2012).

23. X.W. Zhang and L.C. Lei, J. Hazard. Mater., 153, 827 (2008).

24. J. Wang, W. Sun, Z.H. Zhang, Z.Q. Xing, R. Xu, R.H. Li, Y. Li and X.D. Zhang, Ultrason. Sonochem., 15, 301 (2008).

25. Z.D. Meng and W.C. Oh, Ultras. Sonochem., 18, 757 (2011). 